\title{
La imagen estética en el horizonte de la ética del amor
}

\author{
The aesthetic image on the horizon of the ethics of love \\ Víctor Francisco Casallo Mesías* \\ Universidad Antonio Ruiz de Montoya, victor.casallo@uarm.pe \\ Recibido el 30 de octubre de 2020, APRoBAdo El 18 dE NOVIEMbre 2020
}

\begin{abstract}
RESUMEN
Enesteartículoanalizofenomenológicamente la dimensión valorativa en la contemplación de la imagen estética para mostrar cómo enriquece la apertura del yo al mundo y puede orientarlo al llamado a la renovación ético-cultural propuesta por Husserl como misión de la filosofía. Sitúo este llamado en el horizonte de la ética husserliana de los valores absolutos del amor, donde la maduración ética se entiende como un salir de sí mismo hacia el bien del otro en tanto otro. La fenomenología de la experiencia de la imagen estética explicita su dimensión axiológica y cómo, a partir de ella, es posible acceder a otros mundos de sentido. Propongo que este enriquecimiento estético puede facilitar o suscitar una mirada crítica renovada ante el propio mundo circundante, la cual es condición para el despertar a la autorresponsabilidad última requerido por la fenomenología. Esta apreciación fenomenológica de la imagen estética puede contribuir con una autocomprensión más profunda de una formación ética que aspire a responder a las crisis culturales y políticas contemporáneas.
\end{abstract}

\section{Palabras clave}

Husserl, estética fenomenológica, ética fenomenológica, fenomenología de la imagen estética.

\begin{abstract}
This paper analyzes phenomenologically the value dimension in the contemplation of the aesthetic image in order to show how it enriches the openness of the self to the world and direct him to the calling for the ethical-cultural renewal, proposed by Husserl as the mission of philosophy. I will place this calling against the horizon of the Husserlian ethics of the absolute values of love, where ethical maturation is understood as reaching out outside oneself towards the good for the other qua other. The phenomenological analysis of the experience with aesthetic images brings to light its axiological dimension and, furthermore, the possibility to access other worlds of meaning. I claim that this aesthetical enrichment can facilitate or trigger a renewed insight of the own surrounding world, which is a condition for the awakening to the ultimate selfresponsibility required by phenomenology. This phenomenological appraisal of the aesthetic image can contribute to a deeper self-understanding of an ethical education that aims to respond to the contemporary cultural and political crises.
\end{abstract}

\section{KeYwORDS}

Husserl, phenomenological aesthetics, phenomenological ethics, phenomenology of the aesthetic image.

* (1) orcid.org/0000-0001-7954-5780 Google Scholar

Discusiones Filosóficas. Año 21 No 37, julio - diciembre 2020. pp. 143-161 


\section{Introducción}

La preocupación ética es central a lo largo de toda la obra de Husserl. Su comprensión de la autorresponsabilidad, como ideal de la ciencia, se puede rastrear en sus diferentes textos y cursos. En contraste, la estética no recibió un tratamiento sistemático similar, si bien aparece en el contexto de diferentes discusiones, a veces como tema central. Investigadores como R. Ingarden orientaron su trabajo fenomenológico a una ontología de la obra de arte. Otros, como M. Merleau-Ponty o M. Dufrenne desarrollaron propuestas originales de estética fenomenológica a partir de las desperdigadas reflexiones de Husserl sobre el tema.

En el curso de 1904/1905 recogido en Husserliana XXIII, la investigación epistemológica de la conciencia de imagen da pie al análisis de la imagen propiamente estética. Esta discusión más específica incorporará el tema axiológico y servirá de base para la comprensión del arte en general. En textos posteriores Husserl retomará y desarrollará las categorías, distinciones y orientaciones de esta incursión fenomenológica en la experiencia estética.

En el mundo contemporáneo, la imagen ha cobrado una centralidad mayor, incluso, que en el tiempo de Husserl. Esta nueva cultura de las imágenes audiovisuales no tiene por qué ser entendida como antagonista del pensamiento crítico asociado tradicionalmente al libro en la cultura moderna. En este artículo, haré dialogar diferentes textos husserlianos para destacar cómo la dimensión axiológica en la imagen estética se correlaciona con la forma en la que el yo se deja afectar por el mundo, de manera que puede renovar su mirada y capacidad de agencia. Este diálogo que busca vincular la vivencia de algunos objetos culturales y las exigencias éticas de la vida en comunidad presupone la unidad del pensamiento husserliano como un proyecto empeñado, a través de todas sus ramificaciones, correcciones y precisiones, por la idea de la filosofía como una vida racional fundada en la evidencia. Este llamado filosófico al que Husserl siempre buscó responder, se puede formular, apelando a los títulos de dos de sus textos, como la exigencia de una renovación ético-cultural en respuesta a la crisis de la civilización occidental. Para desarrollar el posible vínculo entre la imagen estética y este llamado a la renovación ética partiré, en primer lugar, de una caracterización de la ética tardía de Husserl como la respuesta personal al llamado del amor como procurar el bien del otro en 
cuanto otro. En un segundo momento, elaboraré fenomenológicamente el aspecto axiológico en la experiencia de la imagen estética. En tercer lugar, discutiré cómo una comprensión más profunda de la ampliación de mundos de experiencia ofrecida por las imágenes estéticas puede colaborar con los esfuerzos de formación ética que aspiran a responder a las crisis de nuestro tiempo.

\section{Ética de los valores del amor}

En esta primera sección caracterizaré la ética del amor husserliana para profundizar en su conexión con la constitución intersubjetiva del yo correlativa a su mundo y destacar el sufrimiento humano en ese mundo en crisis. Esta presentación permitirá introducir el tema de la imagen dentro de esa mirada ética sobre el mundo fáctico.

Para Husserl la razón no admite "ninguna diferenciación entre 'teórica', 'práctica' y 'estética'" (Crisis 308). El entretejimiento entre estos aspectos distinguidos analíticamente en investigaciones previas, le permite defender el ideal de una ética racional que no se limite al utilitarismo estratégico ni se pierda en el emotivismo. En una primera etapa, Husserl muestra en qué sentido hay racionalidad e irracionalidad en la vida afectiva y práctica, en forma análoga pero no idéntica- a las leyes lógicas en la esfera teórica (Vorlesungen 97). Ese paralelismo se aclara en el análisis de la fundación de los actos axiológicos y prácticos sobre los actos cognitivos (Husserl, Ideas 1312), donde la primacía lógica de estos últimos es compatible con la equiprimordialidad de todos ellos (Drummond, Intentional Structure 251). Este yo que valora y actúa es ya un ser dotado de un estrato anímico (Husserl, Ideas 2 230), así como, para percibir el mundo concreto, está ya encarnado en un cuerpo (Husserl, Ideas 2 88). Estos desarrollos le permiten a Husserl replantear el imperativo categórico brentaniano, incorporando el campo concreto de posibilidades prácticas del agente y la motivación enraizada en su vida afectiva (Renovación 43). Posteriormente, esta exigencia es presentada en términos de un llamado dirigido al centro personal del yo para madurar éticamente. Al autodescubrirse y recrearse en los desafíos de su vida particular, el yo personal responde al llamado de hacerse cada vez más auténticamente sí mismo. Esta realización del yo es caracterizada finalmente como el crecimiento hacia el telos del amor ético (Husserl, Espíritu común 140). Vista en conjunto, la investigación husserliana de la ética parte del análisis 
de su fundamento en la razón y culmina exponiendo sus exigencias y plenitud en el amor (Melle 121).

El ideal del amor ético tiene su fundamento en la génesis intersubjetiva del yo personal: el recién nacido necesita ser acogido entre los cuidados de otros que le anteceden en el mundo para que pueda reconocerse como un yo. La actividad propiamente egológica de ese futuro yo personal, tiene como condición la pasividad asociativa desde la que opera su conciencia, ampliando y elevando sus horizontes gracias a esa mediación intersubjetiva. Esta receptividad y orientación a los otros es eminentemente afectiva y práctica (Hart 189). Gracias a ese movimiento de apertura del yo, el mundo va cobrando sentido en un relieve particular de relevancias. Hacer espacio a las perspectivas de los otros, le permite, simultáneamente, autodescubrirse. Sus acciones en el mundo y, sobre todo, aquellas que se dirigen a sí mismo, lo van configurando en una personalidad propia: un sujeto de habitualidades que predelínean cómo se deja afectar -o no- por los objetos, hechos y personas de su mundo circundante (Husserl, Meditaciones cartesianas 121).

La maduración ética se juega en la racionalidad con la que el yo justifica la confirmación, modificación o replanteamiento de quien ha venido siendo. Prolongando la génesis en la que emergió, el yo personal crece cuando, al salir de sí mismo, hace espacio a los otros y avanza a ser más auténticamente quien va descubriendo que está llamado a ser. Así, por ejemplo, puede aprender a renunciar a formas evidentes de satisfacción para poder alcanzar bienes más valiosos y reconocer en un sentimiento desagradable una respuesta afectiva éticamente apropiada, como cuando confiesa hidalgamente una falta cometida (Drummond, Intentional Structure 261). Se puede juzgar racionalmente, entonces, sobre la (in)corrección de emociones y actos. La vida afectiva no se reduce a regularidades causales contingentes, sino que entraña relaciones esenciales a priori en términos de motivación (Husserl, Vorlesungen 106). El yo que se empeña en una vida auténticamente ética responde al llamado para hacerse cargo de la forma en que se deja motivar por su mundo circundante y, en particular, por los otros con quienes convive. Entre las diferentes formas de relación intersubjetiva, el ideal del amor ético radicaliza este movimiento de autovaciamiento orientándolo al bien del otro, es decir, al encontrar la propia dicha en el procurar al otro -sin imponérselo- aquello que le permita a ese otro ser cada vez más auténticamente sí mismo (Hart 344). 
En su ética tardía, Husserl vuelve sobre estos planteamientos desde una reflexión que se sitúa sobre lo fácticamente dado a nuestra existencia (Iribarne 205). El deber ético es formulado, desde esa perspectiva metafísica, como vivir según aquel valor absoluto del amor ante la facticidad del sufrimiento, la muerte y la posibilidad del sinsentido de la vida personal, comunitaria e histórica (Husserl, Grenzprobleme). Situado ante la destrucción inminente del mundo a manos de la idiotez de la propia humanidad, cuando toda posibilidad de logro pragmático se despedaza contra esa destrucción total, parecería que la justificación racional del deber ético no bastara. Husserl afirma que el yo todavía puede encontrar sentido en ese amor que hace espacio al sufrimiento del otro y, en él, al sufrimiento de todo otro, para salir a su servicio. Así, su origen trascendental como un yo acogido en el amor se cumple en el telos de la vida ética solidaria experimentada como dicha.

Husserl plasma esta situación describiendo el ejemplo de una madre que, a pesar de la evidencia de que el mundo va a destruirse, persiste en cuidar amorosamente a su hijo, es decir, en procurar su bien (Grenzprobleme 310). La imagen de la madre doliente pero amorosa, exhibe este ideal de una vida que se abre a los sufrimientos y luchas en toda la historia . La última palabra que la ética puede ofrecer ya no sería para Husserl la fundamentación de un imperativo categórico renovado, sino la investigación del afecto desde el que surge el llamado personal interno del yo, previo a toda justificación racional (Melle 129). Esta forma de sentir y actuar se cultiva en el trato con personas, como la madre del ejemplo, cuyo testimonio de vida cuestiona y enriquece la personalidad ética propia. El yo capaz de percibir así a quien lucha contra el sinsentido a pesar de todo, se abre al valor de la dignidad humana en la actitud del respeto (Drummond, Respect 11). Aunque no todos se encuentren en su vida con alguien así, pueden hacerlo en forma mediata al escuchar los recuerdos de alguien impactado por una persona ejemplar, al leer la narración de Husserl sobre la madre o al ver toda una vida admirable plasmada en dos horas de una producción audiovisual. En lo que sigue, argumentaré que, para la renovación que la fenomenología busca suscitar (Husserl, Renovación 17), la imagen estética puede ayudar a motivar y facilitar situarse en la actitud de comprensión demandada por este cuestionamiento ético que se orienta al amor. 


\section{La dimensión axiológica en la experiencia de la imagen estética}

En esta sección discutiré la dimensión axiológica en la imagen estética para señalar algunos puntos de conexión con la idea de renovación exigida y orientada por la ética del amor. Partiré del análisis de la conciencia de imagen en Husserliana XXIII para centrarme en su discusión de la intencionalidad valorativa específica de la imagen estética. Me apoyaré en textos husserlianos posteriores sobre el mismo tema para mostrar cómo la prioridad axiológica del disfrute estético compromete tanto la receptividad como la participación activa del yo en la medida que apela al proceso constitutivo de su forma de dejarse afectar por el mundo. Esta comprensión husserliana de la experiencia estética le permitirá señalar su convergencia con la orientación al conocimiento y al bien.

La atención del yo es captada en la vida cotidiana por diferentes imágenes, por ejemplo, la fotografía de una persona o la pintura de una catedral imponente. De hecho, todo objeto es percibido por el yo como agradable, curioso, esclarecedor, etc. en su mundo circundante. La idea de un objeto neutro en términos valorativos o prácticos es una abstracción (Husserl, A VI 26 42). Las propiedades valorativas no son un elemento adicional sino una nueva dimensión de sentido en la unidad del objeto (Husserl, Ideas 1 363). La investigación fenomenológica no puede obviar esta riqueza de sentido: con la reducción trascendental el manzano en flor percibido no perderá ninguna de sus cualidades de bello, seductor, etc. (Husserl, Ideas 1 296). Ahora bien, el objeto primario del análisis de la conciencia de imagen recogido en Husserliana XXIII es más delimitado: caracterizar presentificaciones (Vergegenwärtigungen) como la imagen y la fantasía en contraste con la presentación (Gegenwärtigung) perceptiva. Esta discusión epistemológica se abre a la dimensión axiológica cuando se especifica en el análisis de la imagen estética.

La investigación fenomenológica de la conciencia de imagen comienza preguntándose cómo viene a presencia sensible en la imagen lo que no está presente en persona. Esta vivencia se caracteriza como el entrelazamiento de tres formas de intencionalidad dirigidas a sus correspondientes correlatos objetivos: la cosa material (cosaimagen, Bildding) cuya configuración sensible sirve como soporte de la imagen propiamente dicha (objeto-imagen, Bildobjekt), la cual trae a presencia aquello ausente puesto en imagen (Sujet) 
(Husserl, Bildbewusstsein 19). En contraste con el mero ver una cosa material, "ver" una imagen presupone un acto perceptivo cuyo carácter ponente es neutralizado, aunque el contenido sensible de ambos actos es el mismo. La neutralización suspende la dación en persona de la cosa-imagen, pero hace posible el aparecer sensible del objeto-imagen. Éste trae a presencia el Sujet-imagen, aunque no en persona como en el percibir, de manera que podemos advertir una semejanza que no llega a ser identidad (Husserl, Bildbewusstsein 20). La conciencia de imagen es, entonces, una presentificación que presupone como su fundamento una presentación perceptiva neutralizada, la cual tiene como telos, la dación del Sujet en una intuición plenificadora (Rubio 97). Husserl caracterizará más adelante esta estructura de la conciencia de imagen como un conflicto entre las intencionalidades involucradas, diferente del conflicto entre percepciones discrepantes (duda) o entre ilusión y percepción (Bildbewusstsein 40).

La imagen aparece en una espacio-temporalidad propia (Husserl, Bildbewusstsein 537), fruto de las intencionalidades en conflicto. Esta afirmación vale también para imágenes como la pintura, caracterizadas en actitud natural como estáticas. La tridimensionalidad, proporciones, punto de vista, etc., propias de la espacialidad del objeto-imagen, contrastan con la del Sujet representado, como la pintura de la catedral respecto al edificio mismo. En este último caso, la persona que contempla puede moverse y, por ejemplo, ver la parte posterior de la catedral, lo cual es una posibilidad cerrada en el caso de la pintura. La imagen se muestra, sin embargo, en cierta espacialidad. En la imagen encontramos un arriba y abajo, una derecha e izquierda, un adelante y atrás, etc., análogos a las direcciones del mundo vivido cotidianamente, las cuales suponen un cuerpo vivo que siente, se siente y es capaz de moverse a voluntad (Husserl, Ideas 2 87). Más aún, el sentido en el que se vive la imagen rebasa intencionalmente el marco del cuadro: el mundo imaginario que ofrece es mayor que el área rectangular actualmente visible (Husserl, Bildbewusstsein 46). Análogamente los personajes, objetos y el paisaje pueden ser experimentados como teniendo profundidad, aunque podamos comprobar, en un giro atencional, que son planos.

A su vez, la temporalidad de la imagen contrasta con la temporalidad objetiva del mundo cotidiano del sujeto, pero también con la 
temporalidad inmanente de la vivencia. Husserl llama la atención sobre esta enigmática posibilidad de sentir movimiento en la imagen estática -el jinete está detenido en la fotografía y, sin embargo, lo aprehendemos como moviéndose- y la describe como la irrupción de un "no ahora" en un ahora vivido con el que no se confunde (Bildbewusstsein 47). Por otro lado, el movimiento puede tener un sentido más amplio que el cambio de ubicación. La acción puesta en imagen -un cuchillo levantado amenazadoramente o una mirada apasionada- puede permanecer como un ahora que se prolonga significativamente.

Experimentarelmovimiento presupone,comoseñalamos, lacapacidad del cuerpo vivo para ser afectado por su mundo circundante y para desempeñarse en él. En el caso de la imagen, este involucramiento del cuerpo y, por tanto, del yo, abre la posibilidad de sumergirse en otros mundos fácticamente imposibles, dado que el Sujet imagen no tiene porqué corresponder a un objeto realmente existente. La imagen, desde esta perspectiva fenomenológica, es una irrealidad: no existe ni en la mente ni fuera de ella (Husserl, Bildbewusstsein 22), es el correlato intencional de una forma peculiar de conciencia y, por tanto, es ajena a las posiciones ontológicas sobre lo que se acepte como existente o no. La imagen hace presente otro mundo, un mundo ideal "que es un mundo por sí mismo" (Husserl, Bildbewusstsein 46). En el caso de las imágenes audiovisuales de la televisión, cine o video, estos mundos y sus posibilidades espacio-temporales son desarrolladas en estructuras y sentidos más complejos: lo que aparece "fuera de cuadro" puede ser significativo para la acción que se desenvuelve (el sonido de una puerta cerrándose o de un disparo que no se ve en la pantalla), una escena nos aparece desde puntos de vista y acercamientos cuya sucesión sería imposible para nuestra percepción normal (vemos a través de los ojos de la víctima y luego desde los del victimario), la continuidad temporal puede ser entendible aunque omita miles de años en el desarrollo de la historia (elipsis) o regrese un momento al pasado para luego continuar (analepsis), etc. En contraste con el carácter proteico del fantasear, la continuidad de sentido en la que se da la imagen le ofrece a Husserl un modelo más consistente para el análisis de experiencias como ver cine (Bildbewusstsein 61). El modelo es proyectado al arte en general cuando propone considerar el objeto estético ofrecido en la obra de arte como una forma de imagen (Husserl, Bildbewusstsein 41). Las consideraciones husserlianas sobre la imagen estética particularizan este análisis y permiten apreciar la centralidad de la intencionalidad valorativa al contemplarla. 
La conciencia de imagen no exige una actitud estética; así como no toda imagen se ofrece como objeto estético. En la contemplación de una imagen estética como una pintura de Rembrandt, el interés no se dirige, en general, a la existencia real de lo representado. Esta última es puesta entre paréntesis en una neutralización específica de la actitud estética, diferente de la que hace posible el surgimiento del objetoimagen (Ferencz-Flatz 492). Esta actitud permite al sujeto enfocarse en el cómo del aparecer del objeto; pero, a diferencia del interés cognitivo o práctico en el fenómeno -propio de la ciencia-, permanece en la intención valorativa (Husserl, Bildbewusstsein 441; Ideas 2 38). El mundo circundante del yo se le abre en un relieve de sentido sobre el cual cada objeto se presenta como más o menos significativo. El interés que guía la actitud del yo puede tornarse sobre sus propiedades descriptivas o valorativas. Si el interés que define la actitud científica ejecuta de una forma determinada los actos dóxicos para constituir objetividades teóricas (Husserl, Ideas 233 ), las objetividades valorativas se fundan en tomas de posición emotivas sobre el cómo aparecen esos contenidos dóxicos al yo que contempla. Esta actitud se constituye ante la obra de arte como el "abandonarse activo del estético 'estarocupado-con-ella-en-el-agrado', del gozo estético entendido como acto, el objeto, dijimos, es objeto del disfrute" (Husserl, Ideas 2 38). El valor se constituye "en la emoción como aquel abandono disfrutante preteórico (en un sentido amplio de la palabra) del sujeto-yo sensible" que Husserl denomina Wertnehmung (valicepción) -por analogía con la Wahrnehmung (percepción)- para destacar su carácter receptivo y activo (Ideas 2 39). Por eso, un personaje, una situación o una escena trágicos, plasmados en una imagen, pueden ser valorados profundamente, al punto de postergar otras actividades prácticas del sujeto en su mundo circundante cotidiano, para entregarse a su contemplación.

La imagen estética - y, en general, la obra de arte - es axiológicamente intuida, no sólo sensiblemente intuida (Husserl, Ideas 238). Sin confundir la esfera lógica con la axiológica, Husserl señala una analogía: en la contemplación puede haber intuiciones inadecuadas que buscan su plenificación en el gozo (Freude) estético (Bildbewusstsein 390; Ideas 2 40). En su manuscrito Ästhetik und Phänomenologie precisa que así como el interés en el fenómeno no es exclusivo de lo estético, tampoco lo es el gozo: este se puede dar en la percepción, pero en la vivencia estética se trata del gozo ante el aparecer (Husserl, Ästhetik 12a). El yo entregado a la contemplación se empeña en plenificar esas intenciones. Así como en el percibir cotidiano se busca "puntos de máxima claridad perceptiva" 
(Ferrer 66) donde el objeto se muestre en forma óptima para su aprehensión (Husserl, Passiven 23), en la experiencia estética se escoge la aparición más conveniente, aquella que contenga la complexión sensible máxima en orden a despertar el agrado (Husserl, Ästhetik 12b).

La estructura constitutiva de la imagen estética va cobrando sentido y profundizándose con esta participación del yo. La desemejanza entre el Bildobjekt y el Sujet no equivale inmediatamente a una deficiencia del medio artístico o del artista -, también puede ser ocasión de mayor valor expresivo, como el grabado de un rostro angustiado plasmado en trazos toscos. Incluso las propiedades materiales del Bildding podrían sumar a ese valor expresivo, por ejemplo, si el grabado se hace sobre una madera, como en El profeta de Emil Nolde (1912). Quien contempla la imagen, dota de sentido esas desemejanzas a partir de las sedimentaciones de su sensibilidad cultural, activadas por la atracción estética. Esta riqueza de sentido supone comprender al objeto estético más bien como una suerte de mundo de experiencia valorativa o, como lo denominará M. Dufrenne, una atmósfera de mundo (168) en la que nos podemos sumergir. En la imagen, el Sujet traído a presencia nos mira (Husserl, Bildbewusstsein 30) y, por ejemplo, "somos transportados a la magnífica vida opulenta y actividad de los grandes venecianos del siglo dieciséis", plasmada por el Veronés (Husserl, Bildbewusstsein 37).

En Ästhetik und Phänomenologie, Husserl extiende estas consideraciones al arte en general. Precisa, por ejemplo, cómo en el caso del texto literario, lo relevante no es el inventario detallado de lo que hay en ese mundo -sus objetos o hechos-, sino el ser alcanzado, envuelto y trasladado afectivamente a ese mundo alternativo (Husserl, Ästhetik $5 b)$. Estas posibilidades son una suerte de direcciones sugeridas implícitamente por el artista, las cuales el yo explora valorativamente a través de la fantasía (Husserl, Ästhetik 9a).

Husserl optará posteriormente por la fantasía como modelo para comprender la vivencia del arte en general, para poder dar cuenta también de experiencias como el teatro, donde resultaría forzado hablar de neutralización o figuración (Abbilden) (Husserl, Bildbewusstsein 514). En todo caso, las distinciones epistemológicas entre imagen y fantasía mantienen su validez para clasificar diferentes formas de arte en las páginas de Ästhetik und Phänomenologie escritas entre 1914 y 1916 y publicadas en Husserliana XXIII (Husserl, Bildbewusstsein 540). Esta diferenciación permite a Husserl explorar las relaciones del arte con 
otras esferas de la experiencia humana. El arte realista transporta al yo a un mundo que recorre valorativamente para disfrutarlo en plenitud intuitiva, aunque siempre dentro de un marco (Rahmen) establecido. Opera como una "biografía" del tiempo que, sin ser ciencia sino arte, comunica conocimiento (Husserl, Bildbewusstsein 541). Por otro lado, el arte idealista se despliega en una actitud normativa que no solo plasma valores y el conflicto entre ellos. Sin moralizar ni parodiar busca "inflamar el amor al bien en nuestras almas" (Husserl, Bildbewusstsein 542). Finalmente, el arte puede, en un nivel más alto, ser filosófico y metafísico: elevarnos a la idea del bien y a la divinidad, alcanzar el fundamento del mundo y unificarse con él (Husserl, Bildbewusstsein 542). Husserl ve posible aquí un cultivo de los actos valorativos propios de la experiencia estética que se esfuerce por su plenificación última en una salida de sí hacia el origen y fin definitivos.

Una confianza similar se expresa en su carta al poeta Hugo von Hofmannsthal (1907): la actitud filosófica y la actitud estética se asemejan en dejar al fenómeno aparecer desde sí mismo, liberándolo de los intereses impuestos por la actitud natural. El artista permanece en ese desinterés recogiendo materiales para crear, mientras el fenomenólogo trabaja en su fijación conceptual (Husserl, Briefwechsel 7 135). Ambos, sin embargo, nos remontan al abismo del problema del conocimiento, el cual solo se resuelve poniendo todo en cuestión. En la medida que la experiencia estética se ofrece como una invitación provocativa para salir de sí e internarse en otro horizonte espaciotemporal, sensorial y valorativo, el yo personal puede revivir y reactualizar su propia experiencia de autoconstitución originaria, correlativa a la constitución de un mundo que comparte desde siempre con la comunidad que lo acogió y cuidó. Así, se puede poner en cuestión su percepción y valoración habituales del mundo, los objetos y los otros. Esta posibilidad de renovación personal no es exclusiva del arte, pues, de hecho, los objetos estéticos no se limitan a las obras de arte. Husserl no sitúa la investigación estética en el problema del juicio o la belleza, sino en la aisthesis (Embree16). Una experiencia estética cotidiana, como contemplar el azul profundo del cielo, tiene a la Wertnehmung como el eje de apertura del sujeto al mundo y cómo este se le puede dar (Husserl, Ideas 2 37). Si el yo es capaz de advertirlo, el encuentro con una persona éticamente admirable en su lucha contra el sufrimiento también puede ser ocasión de esa renovación que le permite salir de sí mismo y hacerse más auténticamente quien está llamado a ser. Finalmente, puede 
encontrar en su comunidad cultural imágenes estéticas de hechos y personas reales o ficticias que lo inviten a esa misma apertura.

\section{El potencial ético de una reconsideración fenomenológica de la imagen estética}

En esta tercera sección mostraré cómo las discusiones precedentes enriquecen la comprensión científica de la imagen estética en una comunidad cultural. Esta comprensión permite advertir el potencial de esta experiencia estética para fortalecer una formación humana que aspire a responder éticamente a las crisis que nos toca enfrentar.

La imagen con pretensiones estéticas tiene un lugar eminente en el mundo contemporáneo, atravesando diferentes culturas. La complejidad de la experiencia de imagen muestra la necesidad de atender a sus diferentes niveles constitutivos para comprender su variedad de espacios y formas en esas culturas. En las últimas décadas, estos espacios y formas se han transformado y convergen, crecientemente, en la pantalla de un ordenador o un teléfono móvil. No pocas veces la educación escolar y la investigación académica han desdeñado estos mundos de experiencia o los han culpado apresuradamente por diversas patologías sociales y personales (Eco 42). La reflexión fenomenológica sobre la imagen estética y su rol en el proceso de integración a una comunidad cultural puede contribuir con una formación que quiera comprender el mundo circundante y la sensibilidad de las nuevas generaciones para motivar su maduración ética. Esta comprensión es la forma de conocimiento propia de las Geisteswissenschaften que se esfuerzan por comprender empáticamente el horizonte motivacional que constituye el mundo circundante del otro. Estas ciencias de la cultura se fundan en la empatía (Husserl, Ideas 2 277), la cual no es sólo un recurso metodológico, sino la dinámica fundamental de constitución recíproca entre el yo y el otro.

El concepto de empatía (Einfühlung) ha atravesado desde el romanticismo alemán una complicada historia en la que se le ha asociado con la estética, la culminación unitiva del conocimiento y la posibilidad de comprensión del otro (Nowak 323). Husserl toma el término de Theodor Lipps, quien interpretaba justamente la experiencia estética como una forma de empatía. Le reprocha una insuficiente diferenciación entre las variedades de expresión 
corporal y refugiarse en una noción imprecisa de instinto (Husserl, Intersubjektivität 24), si bien coincide en reconocer su carácter aperceptivo, intuitivo aunque no originariamente (Moran 292). Husserl terminará por considerar equívoco el término mismo de Einfühlung (Intersubjektivität 335), pero la discusión le habrá permitido centrar el problema en el acceso a la vida espiritual - y no solo emocional - del otro. El espacio de aparición de esa vida es la corporalidad. El medio original de intercomprensión no es el lenguaje, sino la interacción corporal directa entre uno y otro; por eso la fundamentación de las ciencias culturales debe comenzar con el análisis fenomenológico de esta comprensión corporal (Lohmar 43). Este análisis expone, desde la presencia primordial del cuerpo propio y ajeno, la constitución originaria en la que el otro emerge ante el yo como un auténtico alter y no sólo como una mera proyección del ego (Husserl, Meditaciones cartesianas 154). En esa línea, las ciencias culturales deben preservar esa misma distancia respetuosa que advierte contra la cosificación de ese otro, incluso con el pretexto de procurar su bien.

Esta perspectiva afina la percepción de la investigación que busca comprender la vida de una comunidad cultural. Le permite advertir, por ejemplo, cómo se constituyen los valores de lo sagrado y lo digno en la incorporación del infante a prácticas determinadas corporalmente como reverencia, silencio, forma de desplazarse o vestirse, etc., a partir de las cuales cobran sentido las explicaciones lingüísticas posteriores (Lohmar 44). El ejemplo de lo sagrado permite considerar, además, el rol fundamental de las imágenes como objeto de contemplación, si bien no únicamente estética. En el horizonte más amplio de las culturas en nuestra época de comunicación global, la imagen estética tiene una presencia relevante en los procesos de formación de identidad, (falta de) reconocimiento y modos de comportamiento. En este sentido, el análisis de una imagen estética compromete implícitamente el análisis de todo el complejo de imágenes del que forma parte y el análisis de toda la cultura donde toma lugar (Flusser, Fotografía 43). La fenomenología de la imagen estética puede aportar decisivamente a esta investigación.

Ante la posible objeción de que se estaría incurriendo en una confusión esteticista al vincular la imagen y experiencia estéticas con la responsabilidad ética, hay que reiterar que el punto de interés es cómo esta experiencia apela a la forma en la que el yo sale de sí mismo para percibir 
y dejarse motivar de otra manera por un mundo alternativo y, por tanto, cómo puede modificar y enriquecer la actitud natural en la que vive su mundo cotidiano. En coherencia con los planteamientos de la ética husserliana del amor, la salida de sí mismo hacia al otro como telos orientador de la maduración ética, debería ser un criterio central en el proceso formativo de niñas, niños y jóvenes. Por el contrario, ya desde el tiempo de Husserl, la educación y la ciencia, afanadas en el logro de competencias utilitaristas, apenas dejan espacio a la pregunta por su sentido. Formar éticamente no se limita a planificar y realizar acciones, sino que involucra cultivar una forma de percibir, sentir y responder apropiadamente a cada situación concreta. Cualquier esfuerzo de renovación educativa y cultural debería tener presente esa amplitud de la vida del yo en formación. Cuando los discursos racionales de la educación, la ciencia, la política y la filosofía parecen haber caído en descrédito, la experiencia de crear, compartir y discutir imágenes estéticas ofrece, para fenomenólogos de la comunicación como Vilém Flusser, un rescoldo para intentar encontrar sentido reaccionando creativamente al sistema global que parece sobrepasar cualquier capacidad de acción, para empezar, sobreproduciendo imágenes que anestesian la percepción en vez de renovarla (Flusser, Imágenes 47). Se trata de procurar encuentros con los otros y con uno mismo que hagan más creíble esa posibilidad de actuar y crear. La experiencia estética de mundos de ficción amplía inconmensurablemente el horizonte de esos posibles encuentros (Drummond, Respect 23). Hoy, esos mundos están constituidos, junto a la literatura tradicional, por historietas, series de televisión, películas, etc. El desafío es saber discernir y cultivar esa experiencia, respetando su dinámica propia de plenificación imaginativa.

El ejercicio imaginativo de la salida de sí mismo hacia el otro permite, en el ámbito de la política, el cultivo de las actitudes fundamentales de las que pretende la democracia (Arendt 18). La formación en la capacidad de considerar el mismo mundo que compartimos desde un punto de vista -cognitivo, valorativo, práctico- diferente es la concreción del pensamiento crítico como práctica educativa y política. Martha Nussbaum ha destacado cómo el cultivo educativo de la experiencia estética fortalece estas capacidades democráticas y cómo su creciente descuido actual profundiza las crisis políticas y los esfuerzos de desarrollo social (23). Esa apertura orientada al otro 
nos permite también volver sobre los puntos ciegos propios como comunidad política: la insuficiencia del reconocimiento mutuo entre nosotros (Nussbaum 106). En estos contextos de crisis, hacer espacio al mundo del otro no se limita a alimentar la curiosidad de novedades sobre otras culturas. Reconocer esos mundos en su alteridad implica dejar que se hagan presente las imágenes de sus desconciertos, incongruencias y, especialmente, su sufrimiento. Un percibir y sentir que se abran a ese sufrimiento no solo se exponen a la desesperación, sino que se pueden abrir a la esperanza en el amor.

El ejemplo husserliano de la madre que cuida a su hijo ante la inminencia del fin del mundo hoy se plasma muchas otras imágenes de sufrimiento que deberíamos traer a presencia en las aulas, las investigaciones y el espacio público. A menudo debemos reconocer que, al menos inicialmente, ellas conmueven y mueven a las generaciones jóvenes más que los textos que nos movilizaron en un mundo que todavía no conocía las redes digitales de comunicación. Estas imágenes no siempre necesitan exponer figurativamente cuerpos dolientes o poner en los diálogos de sus personajes consideraciones éticas. Las sensibilidades de públicos y creadores toman diferentes formas según culturas y momentos históricos. Para no pocas personas, sus sufrimientos y esperanzas se plasman en imágenes, las cuales valoran especialmente en sus luchas cotidianas. Husserl trabajó el grabado de Durero El caballero, la muerte y el diablo en su análisis de la imagen y la neutralización en Ideas 1 (347), pero lo refiere también a sus penurias personales en otros textos más personales (Thiel 80), especialmente en la carta a E. Fink luego de la ascensión de Hitler al poder (Briefwechsel 4 91). La imagen puede ser una compañía que haga un poco más perceptible la esperanza para compartirla con otros. Esta dimensión pública de la imagen abre un campo todavía más amplio de investigación sobre la autoidentificación y acción comunitarias, el cual escapa a los objetivos de este texto.

En las imágenes estéticas que hoy nos resultan más cercanas y significativas, es posible discernir la dimensión ética en forma de una pregunta o sugerencia de posibilidad. Dependerá de los participantes en el diálogo formativo y sus propias interrogantes. En todo caso, cuando una imagen $u$ otro objeto nos expone a nuestra fragilidad en la apertura imaginativa propia de la experiencia estética, nos ofrece una posibilidad de diálogo para preguntarnos 
cuál es el valor del mundo y de la vida. Esas preguntas pueden ser el comienzo de un camino de renovación personal y social que se haga responsable de construir una comunidad ética de amor desde las crisis contemporáneas.

\section{Conclusión}

El horizonte metafísico de la ética husserliana tardía permite profundizar en cómo la imagen del ser humano sufriente se puede abrir a los valores absolutos de un amor que lo orienta e impulsa. El análisis fenomenológico de la imagen estética muestra cómo su dimensión axiológica abre un mundo de experiencia en el que el yo personal se puede sumergir saliendo de sí, ampliando y profundizando la perspectiva desde la que puede apreciar su mundo, a los otros y a sí mismo, enriqueciendo la autenticidad de su (auto)reconocimiento. Una investigación más profunda de las variedades contemporáneas de la experiencia de la imagen estética, permitiría comprender y aprovechar mejor su potencial ético para los esfuerzos de formación ética que aspiran a asumir responablemente los desafíos de un mundo en crisis.

\section{REFERENCIAS}

Arendt, Hannah. The Promise of Politics. Schocken Books, 2005.

Drummond, John. "Respect as a Moral Emotion: A Phenomenological Approach". Husserl Studies. Feb. 22 (1) 2006, 1-27. [Respect]

Drummond, John. "The intentional structure of emotions". Logical Analysis and History of Philosophy - The Philosophy of Edmund Husser.

Dufrenne, Mikel. The Phenomenology of Aesthetic Experience. Northwestern University Press, 1979.

Entis Verlag, 2013. 244 - 263. [Intentional Structure]

Eco, Umberto. Apocalípticos e integrados. Barcelona: Editorial Lumen, 1984. Print.

Ferencz-Flatz, Christian. "The Neutrality of Images and Husserlian 
Aesthetics". Studia Phaenomenologica, Jan. 9 (1) 2009: 477-493. Print.

Ferrer, Jesús G. "Percepción, conciencia de imagen y consideración estética en la fenomenología husserliana". Eidos No 10 (2009), pp. 52-91.

Flusser, Vilém. Una filosofía de la fotografía. Madrid: Síntesis, 2001. Print. [Fotografia]

---. El universo de las imágenes técnicas. Elogio de la superficialidad. Buenos Aires: Caja Negra, 2017. Print. [Imágenes]

Hart, James. The Person and the Common Life. Studies in a Husserlian Social Ethics. Dordrecht: Kluwer Academic Publishers, 1992. Print.

Husserl, Edmund. Manuskript A VI 1. Ästhetik und Phänomenologie. (Manuscrito inédito), 1907. Print. [Ästhetik]

---. Manuskript. A VI 26. Zur allgemeinen Lehre von der Intentionalität. Beilagen zur Vorlesung. (Manuscrito inédito), 1928. Print. [A VI 26]

---. Husserliana XI. Analysen zur passiven Synthesis. Aus Vorlesungsund Forschungsmanuskripten (1918-1926). Martinus Nijhoff, 1966. [Passiven]

---. Husserliana XIII. Zur Phänomenologie der Intersubjektivität. Texte aus dem Nachlass. Erster Teil: 1905-1920. Martinus Nijhoff, 1973. [Intersubjekvität]

---. Husserliana XXIII. Phantasie, Bildbewusstsein, Erinnerung. Martinus Nijhoff, 1980. [Bildbewusstsein]

---. "El espíritu común (Gemeingeist) I y II. Obra póstuma". Themata. Revista de Filosofía, 4 1987: 131-158. [Espíritu común]

---. Husserliana XXVIII. Vorlesungen über Ethik und Wertlehre 1908-1914. Kluwer Academic Publishers, 1988. [Vorlesungen]

---. Husserliana Dokumente. Briefwechsel. Band 3.4. Die Freiburger Schüler. Springer, 1994. [Briefwechsel 4]

---. Husserliana Dokumente. Briefwechsel. Band 3.7. Wissenschaftlerkorrespondenz. Springer, 1994. [Briefwechsel 7] 
---. Meditaciones cartesianas. Fondo de Cultura Económica, 1996. [Meditaciones cartesianas]

---. Ideas relativas a una fenomenología pura y una filosofía fenomenológica. Libro2. Investigacionesfenomenológicas sobrela Constitución. Universidad Nacional Autónoma de México. Instituto de Investigaciones filosóficas, 1997. [Ideas 2]

---. Renovación del hombre y de la cultura: cinco ensayos. Universidad Autónoma Metropolitana, 2002. [Renovación]

---. Husserliana XXXVII. Einleitung in die Ethik. Vorlesungen Sommersemester 1920 und 1924. Kluwer Academic Publishers, 2004. [Vorlesungen]

---. La crisis de las ciencias europeas y la fenomenología trascendental. Prometeo Libros, 2008. [Crisis]

---. Ideas relativas a una fenomenología pura y una filosofía fenomenológica. Libro 1. Introducción general a la fenomenología pura. Universidad Nacional Autónoma de México. Instituto de Investigaciones filosóficas - Fondo de Cultura Económica, 2013. [Ideas 1]

---. Husserliana XLII. Grenzprobleme der Phänomenologie. Analysen des Unbewusstseins und der Instinkte, Metaphysik, Späte Ethik. Texte aus dem Nachlass (1908-1937). Springer, 2013. [Grenzprobleme]

Iribarne, Juliana Valentina. De la ética a la metafísica. San Pablo, 2007.

Katz, Azul. "Toward a Husserlian Foundation of Aesthetics: On Imagination, Phantasy, and Image Consciousness in the 1904/1905 Lectures". The Journal of Speculative Philosophy. Jan. 30 (3), 2016: 339-351.

Lohmar, Dieter. "On Some Motives for Husserl's Genetic Turn in his Research on a Foundation of Geisteswissenschaften". Studia Phaenomenologica XVIII (2018) 31-48.

Melle, Ullrich. "Edmund Husserl. From Reason to Love", Edmund Husserl: Critical Assessments of Leading Philosophers - Volume 5 / Horizons : life-world, ethnics, history, and metaphysics. New York: Routledge, 2005. Print.

Moran, Dermot. “The Problem of Empathy: Lipps, Scheler, Husserl and 
Stein". Medieval Thought and Beyond in Honor of the Rev. Professor James McEvoy. (Recherches de Théologie et Philosophie Médiévales), Bibliotheca (6) 2004, 269-312.

Nowak, Magdalena. "The Complicated History of Einfühlung". Argument: Biannual Philosophical Journal. Vol 1 (2) 2011, 301 - 326.

Nussbaum, Martha. Not for profit: Why democracy needs the humanities. Princeton University Press, 2010.

Rubio, Roberto. El lugar de la fenomenología en el debate de la reciente filosofía de la imagen. Veritas. Set. 33, 2015: 89-101. 